\title{
Electrochemical dissolution of aluminium in electrocoagulation experiments
}

\author{
Éva Fekete, Béla Lengyel, Tamás Cserfalvi, and Tamás Pajkossy*
}

Institute of Materials and Environmental Chemistry, Research Centre for Natural Sciences, Hungarian Academy of Sciences

Magyar tudósok körútja 2, Budapest, H-1117 Hungary

\begin{abstract}
Six experiments are presented to highlight important features of aluminium dissolution when used in electrocoagulation procedure employed to remove oily contaminations from water. First, using a common oil-in-water emulsion: diluted milk, we show that the electrochemically generated coagulant ions are active only in the first few seconds following their generation - hence the electrocoagulation cells' construction should promote the mixing of the nascent $\mathrm{Al}$ colloid with the water phase. For this reason the use of the narrow-gap cells is suggested. Second, in experiments with Al-Al electrode pairs and dilute, neutral, unbuffered, aqueous solutions we $(i)$ estimate the maximum amount of $\mathrm{Al}$ dissolution on the cathode, and (ii) show how the rate of $\mathrm{Al}$ dissolution changes with frequency if the cell voltage polarity is alternating.
\end{abstract}

Keywords: aluminum, dissolution, coagulation, colloids, water cleaning, specific charge

\section{Introduction}

Electrocoagulation is a collective name of procedures used for removing various contaminants from water, all employing electrochemically generated coagulants, by dissolving "sacrificial" $\mathrm{Al}$ (or Fe) electrodes. Disregarding the effect that the formed ions of high positive charge cause the coagulation of colloids of negative surface charge[1], de-contamination is based on the following effect: In neutral aqueous solutions the hydrolysis of the $\mathrm{Al}^{3+}$ proceeds immediately in the vicinity of the anode, finally yielding $\mathrm{Al}(\mathrm{OH})_{3}$. The growth of the hydroxide particles starts as formation of polynuclear complexes; continues as growth of colloids, which finally merge yielding flocs. During the growth, certain components of the solutions, like the contaminating particles, substances can be sorbed by the flocs, i.e. they can be incorporated in, or adsorbed on, the flocs. As a result, finally the flocs comprise of the Alhydroxide and the contamination. In other words, the process can be named also as heterocoagulation or co-precipitation of Al-hydroxide and the contamination.

The merged particles are separated from the liquid in two ways: precipitate as a sludge ("electroflocculation"), or form a float or a scum ("electroflotation"). The latter technique often makes use of that even the relatively heavy flocs may float if are attached to hydrogen bubbles evolved on the cathode [2].

There exist numerous technical papers on electrocoagulation; for reviews see [3,4,5]. Most of these are on experiments on removal of some, usually organic contaminants from some wastewater. The list of the substances which can be removed is fairly long, see the tabulated list of these in Ref. [6]; many of them are oily emulsions or other colloid-forming organics.

\footnotetext{
* Corresponding author. E-mail: pajkossy.tamas@ttk.mta.hu
} 
Note that the $\mathrm{Al}(\mathrm{OH})_{3}$ coagulant can be generated by simply dissolving Al-salts in water[7]; for comparison of the two methods, see e.g. Ref. [8].

The aim of the present paper is to highlight two conditions of this complex phenomenon/procedure by presenting two groups of experiments related to $\mathrm{Al}$ dissolution. In the first group we emphasize the importance of the simple condition that the generated $\mathrm{Al}$ ions are active coagulants in the first seconds only, that is in their "nascent" state ("in statu nascendi") hence high priority must be given to good convection in cell design. The second group of experiments is focused on the Al electrode's electrochemistry under electrocoagulation conditions with a view to (i) characterize $\mathrm{Al}$ dissolution at the cathode, and (ii) demonstrate a critical issue of applying alternating polarity.

The methods, materials, equipment are intentionally very simple. The electrode is a widely used technical Al alloy; the solutions are bovine milk diluted by tap water, and salted tap water, respectively, for the two groups of experiments. The experiments serve two purposes: first, as demonstration ones, they highlight key points of aluminium dissolution in electrocoagulation experiments. Second, the results have direct relevance to the practical cases of removing oily contaminants from emulsions.

\section{Experimental}

The experiments were carried out in four different cells as follows:

1. A $100 \mathrm{~mL}$ beaker with two parallel, closely $(5 \mathrm{~mm})$ placed $\mathrm{Al}$ plates of about $20 \mathrm{~cm}^{2}$ area with vigorous stirring. Used in Experiment A1.

2. An Al-hydroxide generating nozzle was used in Experiment A2; the details are described together with the experiment.

3. A vertical, flow-through, rectangular channel cell whose two opposite walls were the electrodes (unless otherwise noted $10 \mathrm{~cm}$ length, $5 \mathrm{~cm}$ width, their distance, $d=2 \mathrm{~mm}$ ); the flow direction was up; flow rate could be set and controlled by a peristaltic pump in the $1-16$ $\mathrm{L} / \mathrm{h}(\approx 0.3-4 \mathrm{~mL} / \mathrm{s})$ range. With this cell geometry, such a flow rate results in (in reverse order) $\approx 2-36 \mathrm{~s}$ residence time in the interelectrode space and $\approx 0.3-4.5 \mathrm{~cm} / \mathrm{s}$ linear velocity. Used in Experiments A3, B1, and B3.

4. A two-compartment cell with gas burettes enabled the measurement of gas evolution rates and of mass decrease of the cathode, and monitoring the $\mathrm{pH}$ of the cathode compartment. Vigorous stirring was possible by a magnetic stirrer. Used in Experiment B2.

The Al electrodes were made of technical alumínum alloy plates or rods (AlMgSi0.5 alloy of standard EN AW 6060). For the purpose of comparisons, in few cases, electrodes of different metals were also used made of $(i$ ) iron (carbon steel with $0.2 \% \mathrm{Mn}$ and $0.2 \% \mathrm{Si}$ content of standard 10130); (ii) austenitic stainless steel (EN 1.4404 (ASTM-316L) or similar); (iii) spectral grade $(5 \mathrm{~N}) \mathrm{Al}$.

The metal content of the effluent in cases of Experiments A3 and B3 - after acidifying the samples - was determined by inductively coupled plasma spectrometry (ICP).

Solutions: The diluted milk was prepared by using slightly skimmed bovine milk $(2.8 \%$ fat, $3.6 \%$ protein, $5.0 \%$ lactose, values are all $\mathrm{g} / \mathrm{g} \%$ ) and tap water (hardness around $3 \mathrm{mmol} / \mathrm{L}$ $\mathrm{Ca}^{2+}$, conductivity $0.5-0.6 \mathrm{mS} / \mathrm{cm}, \mathrm{pH} 5.5$; salt concentration $1.3 \mathrm{~g} / \mathrm{L}$ ). The typical dilution is $1: 50$, that is, the total organic matter dissolved is $2 \mathrm{~g} / \mathrm{L}$, for which the chemical oxygen demand (COD, determined by digesting the appropriately diluted sample by potassium bichromate and titrating back the residual bichromate [9]) was found to be around $2.2 \mathrm{~g} / \mathrm{L}$. 
The solutions of the metal dissolution experiments have been made with pure chemicals $\left(\mathrm{Na}_{2} \mathrm{SO}_{4}\right.$ and $\left.\mathrm{NaCl}\right)$ from Reanal or Fluka, in deionized water obtained from an ELGA purewater system.

The coagulation experiments (unless otherwise noted) started with an electrolysis step; then from the liquid some sample was taken in which the flocs were let to grow and settle for a couple of hours (in some cases settling was accelerated by centrifuging). Finally, to characterize coagulation, the turbidity of the supernatant phase was measured through the optical absorption always in a $1 \mathrm{~cm}$ cuvette at $600 \mathrm{~nm}$ wavelength in a spectrophotometer. This quantity, denoted as $A_{600}$, corresponds to approximately 500 FTU (formazine turbidity unit)).

\section{Results}

\subsection{Group A. Electrocoagulation experiments}

\section{Experiment A1: The balance of coagulation}

It has been recognized in many and diverse studies that coagulation efficiency of a given system depends on various parameters: on the concentration of the substance to be removed, on the time and current of electrolysis, on cell geometry and others. It is instructive to define the quantity "specific charge" as the ratio of electric charge, $q$, and contaminant mass, $m$, because of the following reason: The efficiency of contamination removal (i.e. removal of turbidity and/or of COD) vs. $q / m$ plots appear to be independent on contaminant concentration. From such a plot, one can determine the threshold value of charge needed to accomplish the coagulation for any contaminant concentration [10].

The use of specific charge is important, because it characterizes the balance, the coagulant to removed-contaminant mass ratio. Since the measurement method of Bensadok et al. [10] in a re-circulated system is somewhat complicated, we describe a simple procedure to determine the threshold value of specific charge. It is based on an old method, used in the industry as "conventional jar test" [11] in which the result of the effectivity of coagulation is checked through the measurement of the remaining concentration of the colloidal components in the supernatant phase of the flocculated and settled sample ("settled turbidity").

The electrolysis, settling and turbidity determination was performed as described in the Experimental. Turbidity was found to depend separately on electrolysis current, electrolysis time, and concentration of milk. However, the parameter combination of (current $x$ time)/(milk quantity in the dilute solution), i.e. $q / m$ appeared to be the one, from which the extent of coagulation depends on. As shown in Fig.1, with the exception of the range of small $q / m$, turbidity of the supernatant fluid was found to decrease with increasing $q / m$. Beyond a certain $q / m$, the fluid became transparent, its turbidity vanished, indicating a complete (or almost complete) coagulation of the fat/protein emulsion. This threshold value of $q / m$ will be referred to as specific coagulation charge. 


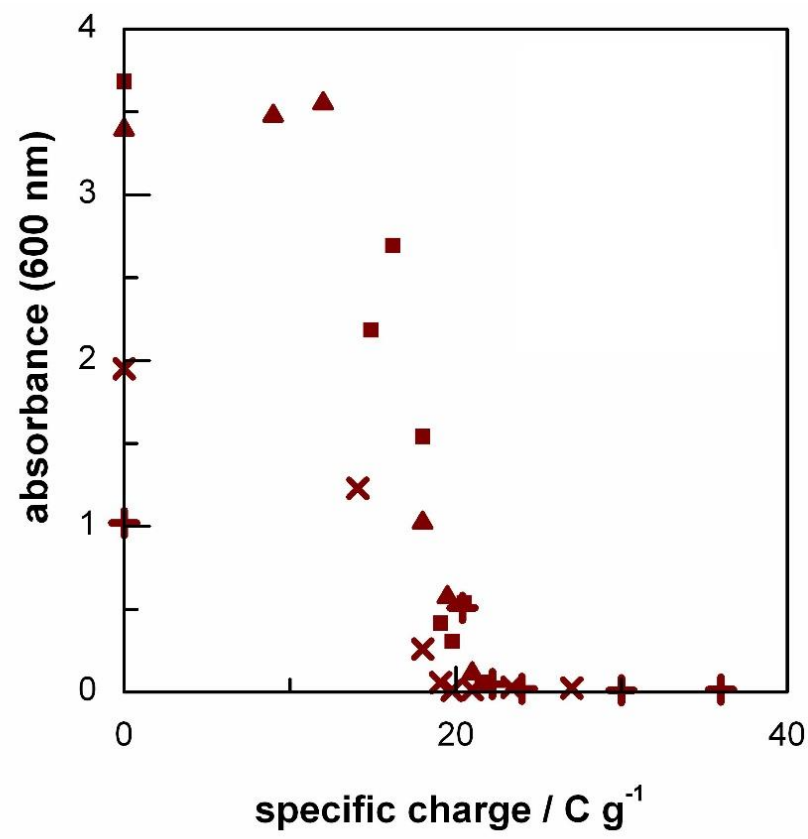

Fig. 1. Turbidity (measured as absorbance at $600 \mathrm{~nm}$ ) as function of specific charge for milk samples of various dilutions (+: $1 \%, \mathrm{x}: 2 \%, \mathbf{\Delta}: 4 \%, \mathbf{\mathbf { m }}: 5 \%)$.

The following notes are due here:

1. There is no concentration-related trend seen in Fig.1, in the vicinity of specific coagulation charge, indicating that the charge needed for coagulation is proportional to the milk content emulsion (at least, in the given concentration range).

2. Though this experiment was performed with the same level of stirring, preliminary experiments revealed that the specific coagulation charge (actually $20 \mathrm{C} / \mathrm{g}$ ) is somewhat dependent on stirring - in general, with faster stirring less charge is sufficient for complete turbidity removal. The results of Experiment A2 strongly support this statement (see below).

3. Optical absorption is a measure of opacity or turbidity, which is, in turn, a measure of concentration of the emulsion. The specific coagulation charge refers to one part of the organics - that of the emulsion - only. COD determination of the cleaned solution leads to the conclusion that electrocoagulation removes approximately $2 / 3(\sim 67 \%)$ of the organic content of this specific system - that is, most of the fat and protein is incorporated in the flocs; the small molecules, like those of lactose remain in solution. Similar measurements in oil emulsions may lead to much higher (>90\%) COD removal efficiencies [12]. This is why the terms "complete turbidity removal" and "complete removal of contaminating substances" must be clearly distinguished.

4. Based on the $\sim 20 \mathrm{C}$ per $1 \mathrm{~g}$ of milk and the $\sim 67 \%$ removal efficiency of the organic matter, the following order-of-magnitude estimation can be made: According to Faraday's law, assuming an $n=3$ charge number, $20 \mathrm{C}$ charge is associated with the dissolution of $1.8 \mathrm{mg} \mathrm{Al}$, leading to $5.2 \mathrm{mg} \mathrm{Al}(\mathrm{OH})_{3}$. From $1 \mathrm{~g}$ of milk - containing $\sim 100 \mathrm{mg}$ organic matter $-\sim 67 \mathrm{mg}$ fat/protein is coagulated. Hence, with $1 \mathrm{~g}$ of $\mathrm{Al}, 67 / 1.8=37 \mathrm{~g}$ organics can be removed. This calculation illustrates how the specific coagulation charge gives us a clue on the mass balance of the coagulant metal and that of the contamination.

5. This experiment carried out with Fe electrode pairs or with another stabilized oil emulsion, namely a drilling fluid, yielded similar results [12]. The metal-to-organic matter ratio for these 
experiments in the same order of magnitude, i.e. on the expense of dissolving one mass-unit of metal, organic substances of 1-2 orders of magnitude larger mass can be removed from water. This mass ratio, however, depends on the nature of the contaminant; it is to be determined for each contamination type, like in Ref. [13]. For example, for two different oil emulsions with different electrodes, the specific coagulation charge values are $60-80 \mathrm{C} / \mathrm{g}$ [14] and $400 \mathrm{C} / \mathrm{g}$ [12].

Conclusion of Experiment A1: For a given solution and given conditions of electrolysis, the sufficient amount of the metal to be dissolved can be determined by turbidity measurements. The specific coagulation charge is a measure of efficiency of the procedure: it characterizes the mass balance of the coagulant metal and that of the contamination.

\section{Experiment A2: Al-hydroxide is an active coagulant just after its generation only}

The electrochemically generated Al-hydroxide, in the moment of its formation is a molecular object. The phase growth, finally yielding macroscopic size flocs is a process on a time-scale of minutes. The coagulating effect of Al-hydroxide prevails only at the beginning of the phase growth, i.e. just after its generation, "in statu nascendi". This is demonstrated in the following experiment.

A cell was constructed in which metal hydroxide generation and coagulation of milk is spatially separated. This is a flow-through cell with a conical $\mathrm{Al}$ anode and a surrounding $\mathrm{Cu}$ cathode (Fig.2a). The outflow gets in the $\mathbf{B}$ beaker through a plastic tube, $\mathbf{T}$. The length of $\mathbf{T}$ can be varied - the time delay, $t_{\mathrm{d}}$, between the metal ion's generation and mixing in the beaker is close to zero $(<1 \mathrm{~s})$ and $15 \mathrm{~s}$ for tube lengths 0 and $100 \mathrm{~cm}$, respectively. For other tube lengths, time delay can be calculated from flow rate and cross section and length of the tube. We performed two sets of experiments:
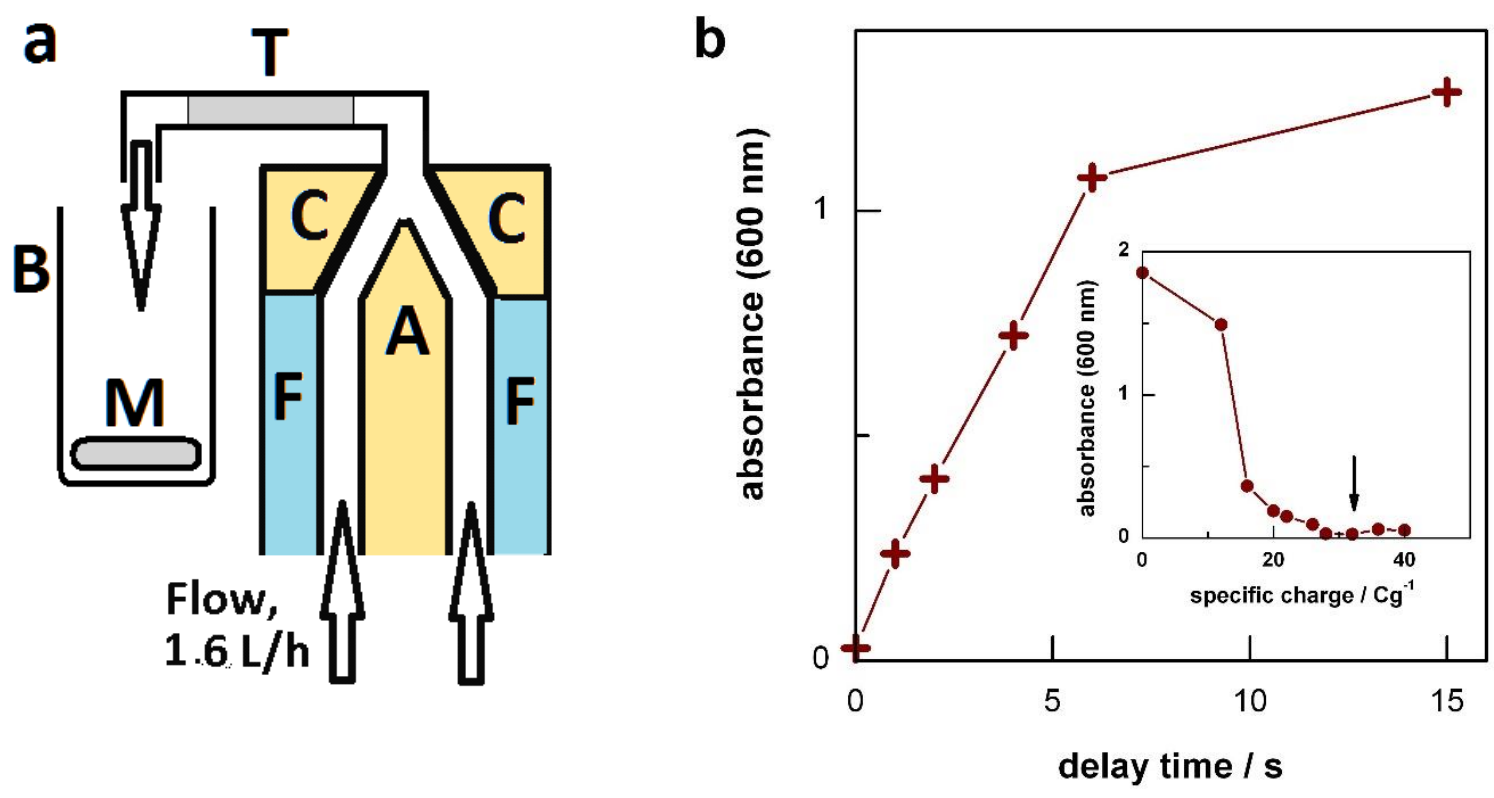

Fig. 2. (a) The experimental setup in which coagulant generation and coagulation are spatially separated. F: cell's plastic frame, A: Al anode, $\mathbf{C}$ : $\mathrm{Cu}$ cathode, $\mathbf{T}$ : plastic tube, B: beaker; $\mathbf{M}$ : magnetic stirrer. (b) Effect of the delay of mixing the generated $\mathrm{Al}$ ions with milk at $32 \mathrm{C} / \mathrm{g}$ specific charge (see arrow on the inset). Inset: Turbidity (measured as absorbance at $600 \mathrm{~nm}$ ) as function of specific charge passed through the cell, when the length of $\mathbf{T}$ is zero. 
1. First no $\mathbf{T}$ was connected to the cell. A certain volume of diluted milk (typically $50 \mathrm{~mL}$, dilution of $2 \%$, i.e. with $1 \mathrm{~g}$ of milk) was filled in the beaker, and the same volume of $10 \mathrm{mM}$ $\mathrm{NaCl}$ solution was pumped through the cell, and electrolyzed by a certain current. The two solutions were intermixed in the beaker in a short time; afterwards the mixture was set aside for a couple of hours for completing the coagulation and settling. Finally its turbidity was measured as absorbance, just as for Experiment A1. In the inset of Fig. 2b we show how the turbidity changes with increasing specific charge. We conclude that the specific coagulation charge for this setup is about $20 \mathrm{C} / \mathrm{g}$; hence if in the next experiment we apply $32 \mathrm{C} / \mathrm{g}$ specific charge, then it is more than enough for complete coagulation.

2. With setting current to cause $32 \mathrm{C} / \mathrm{g}$ specific charge for coagulant generation, we perform the same experiment but with tubes $\mathbf{T}$ of varied length. Turbidity as function of time delay is plotted in Fig.2b. Apparently even a few seconds delay between $\mathrm{Al}(\mathrm{OH})_{3}$ formation and starting of coagulation action significantly decreases the coagulation effect. This is the main conclusion of this experiment.

We note that this experiment with Fe anode yields a much larger $t_{\mathrm{d}}$ time: it is minutes rather than seconds.

Conclusion of Experiment A2: The dissolved Al is active as coagulant for seconds only after its formation.

\section{Experiment A3: Thin-gap cells are more effective than the broader ones}

A cell-construction issue has been raised recently: in the context of phosphate removal by electrocoagulation, Attour et al. [15] found that the width of the gap between parallel electrodes has an effect on removal efficiencies; the narrow-gap $(5 \mathrm{~mm})$ cells are definitely better than the ones with larger gaps $(1$ and $2 \mathrm{~cm})$. No explanation was offered - the aim of this experiment is to demonstrate the reason.

Consider the flow-through cell (see cell No.3 in Experimental) with $d=2 \mathrm{~mm}$. First we electrolyzed diluted milk with a given volumetric flow-rate, $2.35 \mathrm{~L} / \mathrm{h}$ and with varied current. The turbidity vs. specific charge curve is shown in Fig. 3, curve a. In the next series $d$ was increased to $18 \mathrm{~mm}$ while keeping the dilution of milk, volumetric flow rate, and current unchanged. Note that due to the increase of $d$, the flow velocity and also the intermixing of bubbles and various sheaths of the fluid decreased whereas the concentration ratio of the generated Al coagulant and milk was kept constant.

The turbidities were found to be larger indicating that electrocoagulation is much less complete than previously - the difference is rather big around $30 \mathrm{C} / \mathrm{g}$. This is due to that only a small fraction of the diluted milk flew through the cell in the vicinity of the anode where the Al-hydroxide is formed; the majority got mixed to the Al-hydroxide seconds later - when the Al-hydroxide has lost its initially high activity (cf. Experiment A2).

One comment is due here: when the two electrodes are far away from each other and the intermixing effect of the bubbles is less pronounced, then the solution becomes locally acidic in the vicinity of the anode - which itself might cause coagulation of milk. However, this is a minor effect, as it can be demonstrated by repeating the experiment with stainless steel electrodes with keeping the current and the flow rate unchanged (thereby maintaining local $\mathrm{pH}$ changes). In such a cell coagulation is much weaker than with $\mathrm{Al}$ electrodes.

It is instructive the compare the specific coagulation charges obtained in Experiments A1 to A3: The more intensive the stirring/mixing, the smaller is the specific coagulation charge. 


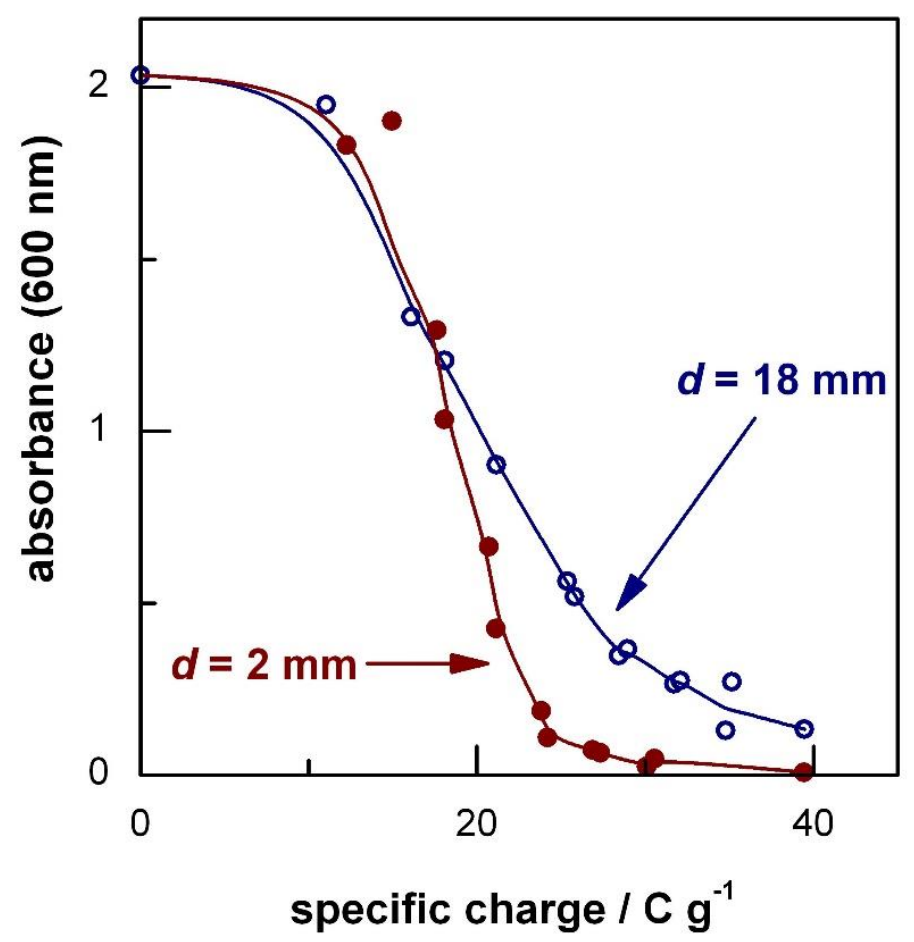

Fig. 3. Turbidity (measured as absorbance at $600 \mathrm{~nm}$ ) as function of specific charge for milk samples of $2 \%$ dilutions measured in a rectangular channel flow-through cell of electrode distance $d$, as indicated for the two curves.

Conclusion of Experiment A3: The Al ions formed at the anode should be intermixed in the solution as fast as possible. With a narrow-gap cell this condition is fulfilled much more than with a broad-gap cell.

\subsection{Group B. Electrochemical dissolution of Al in dilute, non-buffered, neutral aqueous solutions}

As a consequence of the above experiments, electrochemical coagulation should be performed using thin-gap cells. When using Al electrode pairs in such cells, in particular when the aqueous solution is dilute, non-buffered, neutral (or close-to-neutral) three questions of technical relevance appear: What is the dissolution rate $(i)$ of the electrodes in general (ii) in particular of the cathode and (iii) if the polarity of the cell is regularly changed?

\section{Experiment B1: How much $\mathrm{Al}$ is dissolved in an $\mathrm{Al}-\mathrm{Al}$ cell?}

In the first approximation: on the anode $\mathrm{Al}$ is dissolved, its dissolution rate can be calculated using Faraday's law. However, it has been observed in corrosion studies decades ago $[16,17,18,19]$ that $\mathrm{Al}$ is dissolved not only anodically but also under cathodic conditions. Dissolution of the Al cathode in the context of electrocoagulation have also been studied $[14,20,21]$. These measurements - based on hydrogen/aluminium ratio determinations - are suitable to prove that both electrodes are dissolved; however, they cannot provide dissolution rates separately. Here we show a simple measurement for the dissolution rates, separately for the two electrodes. 
We performed the simplest dissolution experiment in the Cell No. 3. with Al-Al electrode pair; $\mathrm{NaCl}$ solution of $1 \mathrm{~g} / \mathrm{L}(\sim 20 \mathrm{mM})$ concentration was pumped through it with $16 \mathrm{~L} / \mathrm{h}$ flow rate and constant current $2 \mathrm{~A}$ was applied. Note that such a large current density, $j=40 \mathrm{~mA} / \mathrm{cm}^{2}$, causes good mixing of the solution due to the strong bubbling on the cathode. Time-to time the cell was disassembled and the weight of the Al plates was measured and plotted in Fig.4. This procedure was repeated up till about $90 \%$ of the anode has been dissolved; dissolution of the metal was found to be more-or-less uniform; the first holes appeared on the anode when its mass has been reduced to its fifth.

We expected no weight loss on the cathode; and expected weight loss according to Faraday's law with charge number $n=3$ on the anode. In contrast, as it is shown in Fig.4, there was some weight loss on the cathode (approximately one tenth of that of the anode; calculated from the slope of the cathode's line, $(9.15 \pm 0.07) * 10^{-6} \mathrm{~g} / \mathrm{C}$, the average dissolution rate is 0.37 $\left.\left(\mu \mathrm{g} / \mathrm{cm}^{2}\right) / \mathrm{s}\right)$. The weight loss on the anode was larger by $15 \%$ than it would follow from Faraday's law. Both findings need interpretation as follows:

The excess weight loss (or, "super-faradaic charge yields") of the anode has recently been studied in Ref. [22] - without reaching a clear conclusion. The study of Canizares et al. [23] leads to the conclusion that chemical dissolution of $\mathrm{Al}$ anode adds to the electrochemical dissolution. Without questioning this statement, we suspect that the clue is in the following finding: By filtering the effluent some fine grey powder could be got, whose composition (Al, $\mathrm{Mg}$, and Si content) - as determined by an X-ray fluorescence (XRF) measurement - was found to be the same as of the Al plate. We conclude that on the anode, along with the Al dissolution, $\mathrm{Al}$ grains are falling out from the metal matrix. This is a rather common case of corrosion, named as intergranular corrosion [24]. This is our explanation for the larger weight loss of the anode. Note that the excess Al disappearing from the electrode in the form of grains does not contribute to coagulation.

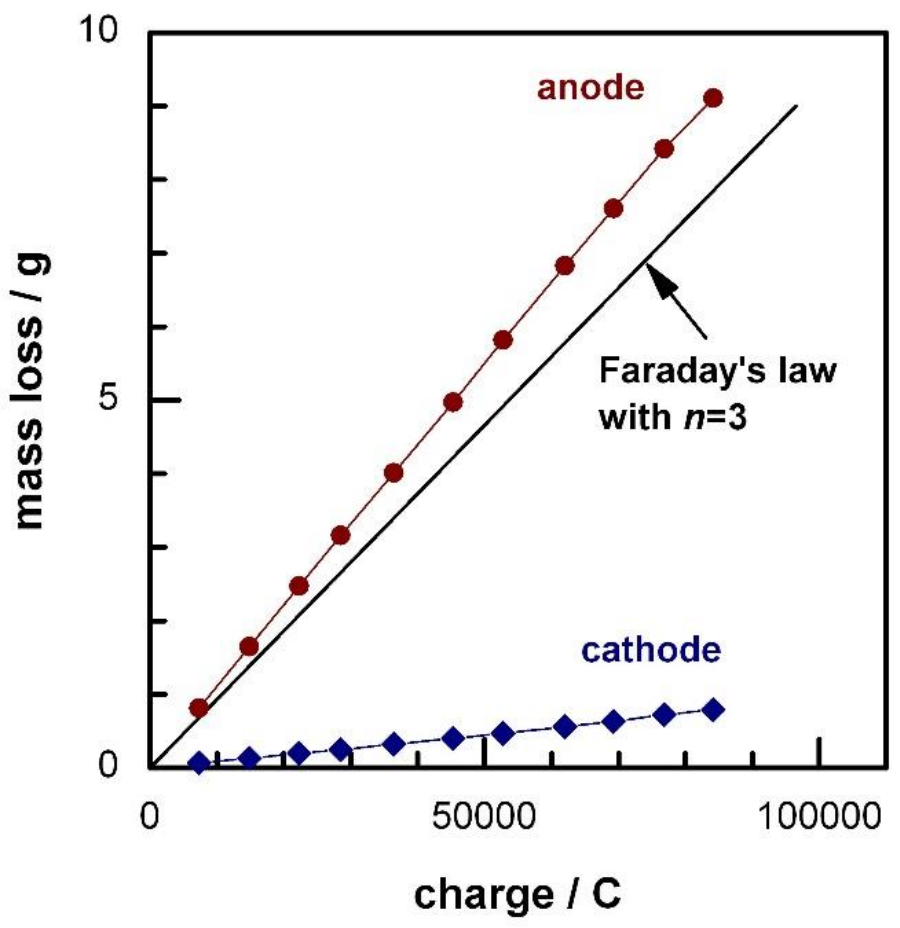

Fig.4. Weight loss of the Al electrodes as function of electric charge passed through the cell. 
The weight loss of the $\mathrm{Al}$ cathodes has already observed and identified as being due to the chemical dissolution of $\mathrm{Al}$ in the locally alkaline solution close to the cathode [14,20,21]. For the necessary conditions of the cathodic dissolution experiments are presented in the next section.

Three notes are due here:

1. We disregard oxygen evolution on the anode, oxygen reduction at the cathode, and hydrogen oxidation on the anode. Were these processes significant, the Al weight loss would have been smaller than that predicted by Faraday's law with $n=3$.

2. The overall excess weight loss of $26 \%$ appears as if the charge number were $3 / 1.26 \approx 2.4$.

3. We have observed the Al anode's "super-faradaic charge yields" under various conditions in almost chloride free tap water, also in diluted milk. In contrast, the cathode's weight loss disappeared (or at least strongly reduced) in diluted milk and in hard tap water. In these cases hazy patches indicated the presence of some thin deposit. Whereas in the case of diluted milk the deposit is of unknown, probably organic, composition; the deposit formed from hard tap water contained much calcium/magnesium, as was shown by XRF measurements. (Scale formation is probably if we take into consideration that close to the cathode the solution is locally alkaline due to which the hydrocarbonate ions form carbonate.) To remove the deposit on the cathode, it seems to be instructive to change polarity time-to-time, see Experiment B3.

Conclusion of Experiment B1: Using a flow-through cell with parallel-plate Al electrodes, almost the complete mass of the anode can be utilized for generating coagulant metal ions. Estimation of the anode's lifetime can be based on simply assuming 100\% Faradaic efficiency of Al dissolution; however, there is some extra mass decrease on both electrodes.

\section{Experiment B2: How much $\mathrm{Al}$ is dissolved at the cathode?}

In Experiment B1, the dissolution rate of the Al cathode - under high-current, strongly mixed conditions in a two Al-electrodes cell - has been determined. In general, $\mathrm{Al}$ - being a reactive metal - readily dissolves in aqueous solutions, provided the protective oxide layer is absent and the solution is either strongly acidic or alkaline. Under cathodic conditions, when the $2 \mathrm{H}_{2} \mathrm{O}+2 e^{-}=\mathrm{H}_{2}+2 \mathrm{OH}^{-}$hydrogen evolution creates $\mathrm{OH}^{-}$ions hence locally alkaline solution, the $2 \mathrm{Al}+6 \mathrm{H}_{2} \mathrm{O}=2 \mathrm{Al}(\mathrm{OH})_{3}+3 \mathrm{H}_{2}$ chemical dissolution reaction may well proceed, resulting in soluble $\mathrm{Al}(\mathrm{OH})_{4}^{-}$ions. The dissolution rate hence strongly depends on all the factors which support or hinder the formation of local alkalinity. In this section experiments are shown leading to the conclusion that the value of dissolution rate obtained in Experiment B1 represents approximately an upper limit.

By doing experiments in the cell No.4 with Al cathode, we observed that the solution becomes strongly alkaline $(\mathrm{pH}>12)$ around the cathode; in addition we may find some dissolved $\mathrm{Al}$ in the cathode's compartment (appearing as white opacity after neutralization). Using that cell, the charge, the volume of the evolved hydrogen, and the mass change of the cathode were measurable quantities, from which the rate of the $2 \mathrm{Al}+6 \mathrm{H}_{2} \mathrm{O}=2 \mathrm{Al}(\mathrm{OH})_{3}+3 \mathrm{H}_{2}$ chemical reaction - e.g. given as $\mathrm{Al}$ dissolution rate - could be computed. With such experiments - with or without stirring the solution by a magnetic stirbar - we found the following trends:

1. In neutral solutions $\left(0.1 \mathrm{M} \mathrm{NaCl}\right.$ or $\left.0.2 \mathrm{M} \mathrm{Na}_{2} \mathrm{SO}_{4}+1 \mathrm{mM} \mathrm{NaCl}\right)$ at the open circuit potential, $\mathrm{OCP}$, (i.e. when $j=0$ ) the $\mathrm{Al}$ dissolution rate is practically zero. Applying a cathodic current of $j=-33 \mathrm{~mA} / \mathrm{cm}^{2}$ density, the dissolution rate is $0.33\left(\mu \mathrm{g} / \mathrm{cm}^{2}\right) / \mathrm{s}$ and $0.45\left(\mu \mathrm{g} / \mathrm{cm}^{2}\right) / \mathrm{s}$ in strongly 
agitated and quiescent solution, respectively. Note that these values are close to that obtained for the $\mathrm{Al}$ dissolution rate in Experiment B1, Fig 4, vide supra.

2. Changing the solution to $10 \mathrm{mM} \mathrm{NaOH}$, we get just the same values for the case when cathodic current flows; however, the $\mathrm{Al}$ is dissolved also at the OCP with a rate of $0.06-0.15$ $\left(\mu \mathrm{g} / \mathrm{cm}^{2}\right) / \mathrm{s}$.

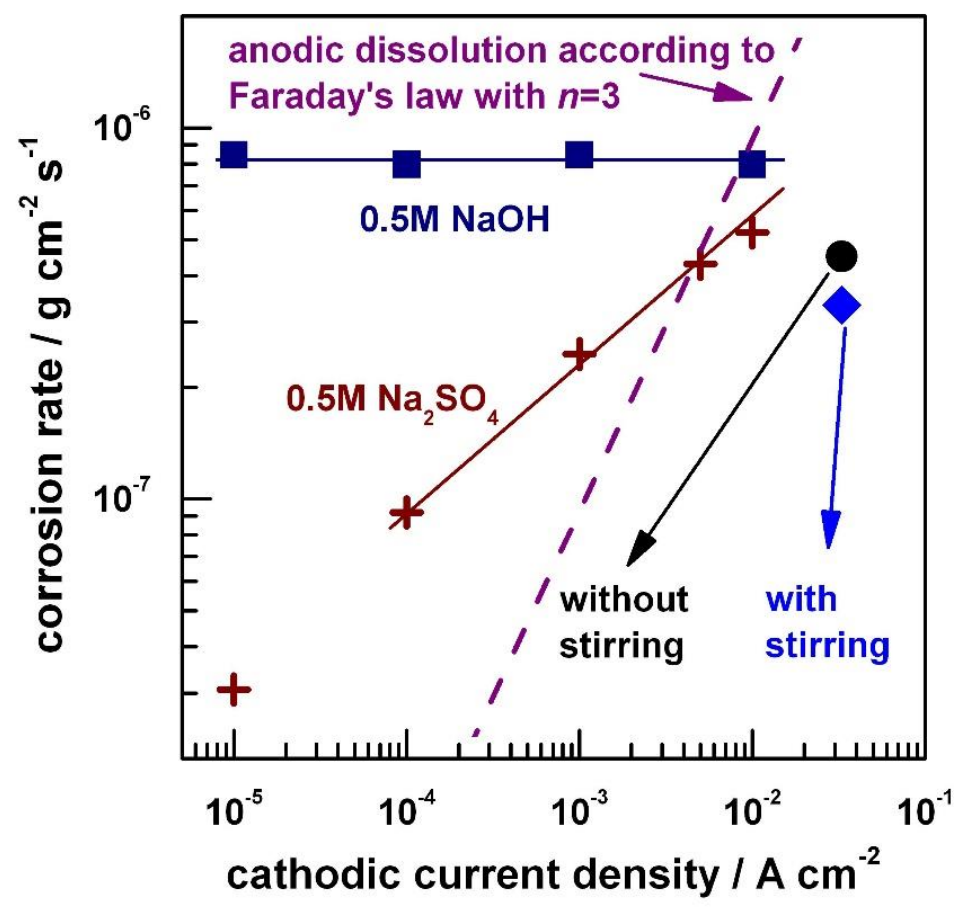

Fig.5. Corrosion rate of $\mathrm{Al}$ as function of the cathodic current flowing through it. Squares and crosses are data for $0.5 \mathrm{M} \mathrm{NaOH}$ and $0.5 \mathrm{M} \mathrm{Na}_{2} \mathrm{SO}_{4}$, respectively, re-plotted from Fig. 1 of Ref.[18]. Diamond and full circle are the rates measured with and without agitation of the solution, respectively, in neutral solutions and also in $10 \mathrm{mM} \mathrm{NaOH}$. Dotted line: anodic dissolution rate, calculated using $n=3$.

3. Finally, we refer to Fig.1 of Ref.[18], whose points are replotted in Fig.5 together with the above rate values. Ref.[18] is a cathodic corrosion study of pure $\mathrm{Al}$, in $0.5 \mathrm{M} \mathrm{NaOH}$ and in $0.5 \mathrm{M} \mathrm{Na}_{2} \mathrm{SO}_{4}$. Note that the reported corrosion rates are somewhat larger than those of our this difference of a factor of 2 is acceptable if corrosion rates of a pure metal and of an alloy are considered. Taking into account that cathodic current density is a measure of $\mathrm{OH}^{-}$ generation at the cathode; we interpret these measurement results as follows:

a. In $0.5 \mathrm{M} \mathrm{NaOH}$ and $0.5 \mathrm{M} \mathrm{Na}_{2} \mathrm{SO}_{4}$ solutions $\mathrm{Al}$ dissolution rate appears to be respectively independent of, and dependent on, cathodic current density, i.e. $\mathrm{OH}^{-}$generation rate. The two respective lines in Fig 5 cross each other around $j \approx 20 \mathrm{~mA} / \mathrm{cm}^{2}$. That is, at this current density local alkalinity reaches that of $0.5 \mathrm{M} \mathrm{NaOH}$, and corrosion rate coefficient levels off. Just as our measurements (diamond) show, at high current densities there is no difference between corrosion rates in alkaline and neutral solutions - the alkalinity of the solution at the electrode surface becomes practically the same. At these current densities bubbling represents a strong agitation of the solution - which acts against accumulation of $\mathrm{OH}^{-}$ions at the electrode surface; this can be somewhat enhanced by strong stirring of the solution (full circle vs. diamond). 
b. In neutral solutions - which are the relevant case in coagulation - the cathodic dissolution rate increases with current density; but much less than proportionally (the slope of line of $0.5 \mathrm{M} \mathrm{Na}_{2} \mathrm{SO}_{4}$ on the log-log plot is about 0.37 ). The anodic dissolution rate (as calculated by Faraday's law) is higher than the cathodic one for $|j|>10 \mathrm{~mA} / \mathrm{cm}^{2}$, cf. Fig.5; consequently, at high and low current densities Al is dissolved mainly on the anode and on the cathode, respectively. Accordingly, the effective charge number appearing in the Faraday's law for the symmetric cells might be any number between 0 and 3 . However, for practical cases of electrocoagulation, usually performed with high current densities the "cathodic dissolution of $\mathrm{Al}^{\prime \prime}$ is always a minor effect to that of the anodic one, and hence $n$ is close to 3 (i.e. the apparent Faradaic efficiency is close to $100 \%$ ).

Conclusion of Experiment B2: The finding that Al ions get into the solution also from the cathode is due to the chemical dissolution of the $\mathrm{Al}$, in the locally alkaline solution produced by hydrogen evolution. The order of magnitude of mass of $\mathrm{Al}$ dissolved in this process is not larger than $0.3-0.6\left(\mu \mathrm{g} / \mathrm{cm}^{2}\right) / \mathrm{s}$. This value represents an upper limit for that process, it might be somewhat different for different $\mathrm{Al}$ alloys, may show some dependence on current density and solution stirring.

\section{Experiment B3: How much $\mathrm{Al}$ is dissolved if cell voltage polarity is alternating?}

As we concluded in Experiment B1, Note 3, to avoid depositions (of any origin) on the cathode, it may be useful to change polarity time-to-time of the electrodes. However, the removal of the passive/inhibiting layer requires some time. As a consequence, with alternating polarity, less metal is dissolved than that would be expected on the basis of Faraday's law. The effect of polarity changes can be easily measured by electrolyzing some electrolyte in a flow through cell (Cell No.3) with a certain constant current of alternating polarity and measuring the metal concentration of the outflow by ICP. The result of such a measurement series is shown in Fig.6. Were the electrolysis carried out with direct current, $d c$, the metal concentration would be $c_{\max }=2.5 \mathrm{mM}$. With increasing the frequency of the polarity changes the amount of the dissolved metal - hence also the apparent Faradaic efficiency decreases. This is a more pronounced effect with Fe electrodes.

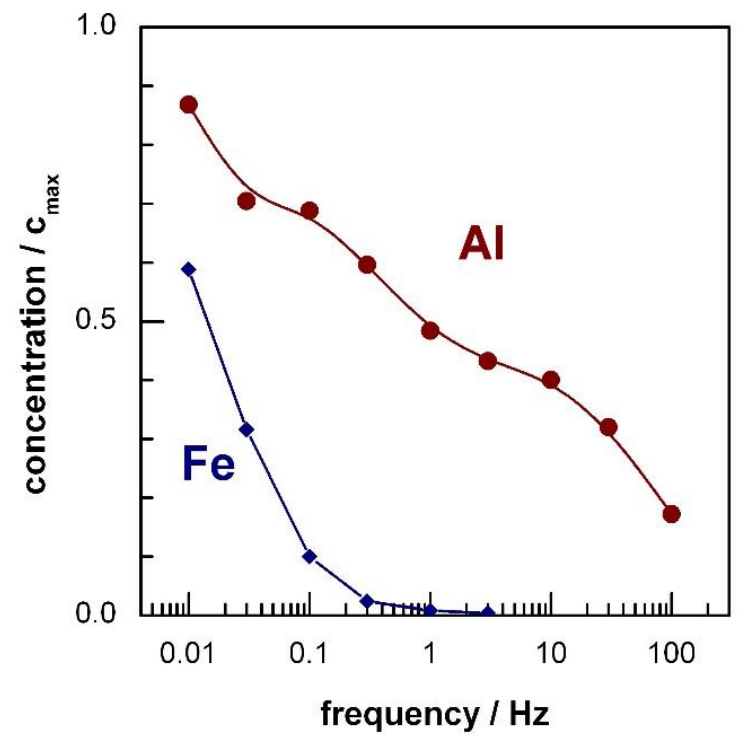

Fig.6. Metal concentration of the outflow of symmetric Al-Al cell as a function of frequency of the current $\left(j=16 \mathrm{~mA} / \mathrm{cm}^{2}\right)$ of alternating polarity. Were $d c$ current applied, the metal concentration would be $c_{\mathrm{max}}=2.5 \mathrm{mM}$. For comparison, data for $\mathrm{Fe}-\mathrm{Fe}$ cells are also plotted. 
Conclusion of Experiment B3: For electrocoagulation, the use of direct current is suggested. If for some reasons polarity changes are preferred then it should not be done more frequently than once in a minute.

\section{Conclusions:}

The summary of our conclusions of each experiment is as follows:

1. Aluminum ions - as coagulants - were found to be active in the first few seconds after their generation: the nascent Al-hydroxide must be intermixed with the solution for good coagulation. Consequently, good convection conditions also at the close vicinity of the electrodes is important. For this reason the use of the narrow-gap cells is suggested.

2. It is instructive to characterize electrocoagulation efficiency by the specific coagulation charge. This quantity gives a clue how much metal is to be dissolved for achieving complete coagulation in a given liquid.

3. Practical information for process engineers: With Al electrodes, $(i)$ almost the complete mass of the metal can be used up. (ii) Though Al ions are generated on both electrodes, at high current densities the anodic dissolution is the dominant and (iii) the polarity of the cell voltage should not be alternated more frequently than once in a minute.

\section{Acknowledgements:}

Financial support of the National Research, Technology and Innovation Office of the Hungarian government through projects KMR_12-1-2012-0386 and OTKA-K-112034 is acknowledged.

\section{References:}

1 Everett DH (1988) Basic principles of colloid science. The Royal Society of Chemistry, London, ch.9.

2 Abrantes LM (2012) In: Bard AJ, Inzelt G, Scholz F (eds) Electrochemical Dictionary, 2nd edn. Springer, Heidelberg, p. 294

3 Mollah MYA, Schennach R, Parga JR, Cocke DL (2001) Electrocoagulation (EC) - Science and Applications. J Hazard Mater 84: 29-41.

4 Vepsäläinen M (2012) Electrocoagulation in the treatment of industrial waters and wastewaters. Thesis, VTT Technical Research Centre of Finland, Espoo, Finland

5 Sahu O, Mazumdar B, Chaudhari PK (2014) Treatment of wastewater by electrocoagulation: a review. Environ Sci Pollut Res Int 21: 2397-2413

6 Emamjomeh MM, Sivakumar M (2009) Review of pollutants removed by electrocoagulation and electrocoagulation / flotation processes. J Environ Manage. 90:1663-1679

7 Duana J, Gregory J (2003) Coagulation by hydrolysing metal salts. Adv Colloid Interface Sci 100 -102: 475-502

8 Canizares P, Martinez F, Jimenez C, Saez C, Rodrigo MA (2008) Coagulation and electrocoagulation of oil-in-water emulsions. J Hazard Mater 151: 44-51

9 Water quality -- Determination of the chemical oxygen demand, ISO-6060: 1989

10 Bensadok K, Benammar S, Lapicque F, Nezzal G (2008) Electrocoagulation of cutting oil emulsions using aluminium plate electrodes. J Hazard Mater 152: 423-430

11 Black AP, Buswell AM, Eidsness FA, Black AL (1957) Review of the Jar Test, Journal (American Water Works Association) 49: 1414, stable URL: http://www.jstor.org/stable/41254753 
Pajkossy T, Fekete É, Cserfalvi T, Lengyel B (2016) Electrocoagulation: an electrochemical process for water clarification. J Electrochem Sci Techn. Doi: 10.5599/jese.218

13 Khemis M, Leclerc JP, Tanguy G, Valentin G, Lapicque F (2006) Treatment of industrial liquidwastes by electrocoagulation: Experimental investigations and an overall interpretation model. Chem Eng Sci $61: 3602-3609$

Khemis M, Tanguy G, Leclerc JP, Valentin G, Lapicque F (2005) Electrocoagulation for the treatment of oil suspensions: Relation Between the Rates of Electrode Reactions and the Efficiency of Waste Removal. Process Saf Environ Prot 83(B1):50-57

Attour A, Touati M, Tlili M, Ben Amor M, Lapicque F, Leclerc JP (2014) Influence of operating parameters on phosphate removal from water by electrocoagulation using aluminum electrodes. Sep Purif Technol 123:124-129

Caldwell BP, Albano VJ (1939) Rate of Solution of Zinc and Aluminum while Cathodic. Trans. Electrochem. Soc. 76:271-285. Doi:10.1149/1.3500282

17 van de Ven EPGT, Koelmans H (1976) The Cathodic Corrosion of Aluminum. J Electrochem Soc 123:143-144

18 Despić AR, Radošević J, Dabić P, Kliškić M (1990) Abnormal yields of hydrogen and the mechanism of its evolution during cathodic polarization of aluminum. Electrochim. Acta 35:1743-1746

Moon SM, Pyun S1 (1997) The corrosion of pure aluminium during cathodic polarization in aqueous solutions. Corros Sci 39: 399-408

20 Picard T, Cathalifaud-Feuillade G, Mazet M, Vandensteendam C (2000) Cathodic dissolution in the electrocoagulation process using aluminium electrodes. J Environ Monit 2:77-80

Mouedhen G, Feki M, Wery MDP, Ayedi HF (2007) Behavior of aluminum electrodes in electrocoagulation process. J Hazard Mater 150:124-135

22 Mechelhoff M, Kelsall GH, Graham NJG (2013) Super-faradaic charge yields for aluminium in neutral aqueous solutions. Chem. Eng. Sci. 95:353-359

23 Canizares P, Carmona M, Lobato J, Martınez F, Rodrigo MA (2005) Electrodissolution of Aluminum Electrodes in Electrocoagulation Processes. Ind Eng Chem Res 44:4178-4185

Uhlig HH (1963) Corrosion Handbook. Wiley, New York, p.54 